market economy, and even of a pluralistic democratic government, to control. The challenge of the book is to ask: If this fear turns out to be justified, how do you order your priorities between security, equity, freedom, and efficiency?

The remedies suggested, as a guide to the decision-maker, are not (most of them) original. Decentralisation is advocated, of course-into small units where local leaders can work for local consensus; so is a negative income tax, to pacify a population which might otherwise revolt during the painful journey from a growth-economy to a steady-state economy; and so is rationing, as a control for scarce resources, rather than reliance on the market price. One attractive idea is to issue a petrol ration to every person over the age of 18 , whether he or she has a car or motor bike

\section{Accounting for cognitive psychology}

The Psychology of Cognition. By Gillian Cohen. Pp. 241. (Academic: London, New York and San Francisco, 1977.) $£ 7.50 ; \$ 15.65$. The Process of Cognition. By Arthur L. Blumenthal. Pp. 230. (Prentice-Hall International: Englewood Cliffs, New Jersey and Hemel Hempstead, UK, 1977.) £7.65; \$10.95.

THE goal of cognitive psychology is to explain how the mind works. Its method is experimental, and its essence can best be illustrated by two of the many phenomena that it has uncovered. First, consider an experiment in which subjects are shown an array of letters that is too large to be reported in its entirety after a single brief exposure. If, immediately after such a presentation, the subjects are instructed to describe only part of the array, then they perform very well regardless of the particular part to which their attention is directed. It seems that there is a sensory buffer that briefly prolongs the effective duration of stimuli. Second, experiments have shown that if subjects are prevented from rehearsing a few digits that they have to remember, then their ability to recall them declines exponentially over time. What is to be made of such phenomena? Cognitive psychologists attempt to account for them in small-scale models cast in the form of flow-chart diagrams in which information flows between boxes with such labels as "sensory buffer" and "short term memory". There can be little doubt that the enterprise is scientific, but it has so far failed to yield a comprehensive account of human mentality. These two books, one by an English psychologist, Gillian Cohen, and the other by an American psychologist, Arthur Blumenthal, attempt in their different ways to deal with this problem.

The Psychology of Cognition concen- or not. The total ration would represent the nation's decision as to how much petrol may be used for private consumption. Owners of ration tickets could then sell them, or the state could buy them back at an agreed price. If the ration is adequate, the temptation to have a black market would be minimised.

This volume, and the four more which are to come, may not offer blueprints to politicians. But the first volume is a healthy reminder to decision-makers that although technological fixes may keep the democratic West going for some time yet, in the long term the problems they-and the people on whose behalf they make decisions - have to solve are not technological; they are moral.

Lord Ashby is Chancellor of the Queen's University, Belfast, and Fellow of Clare College, Cambridge, UK.

trates on language, thinking and problem solving. Each chapter describes some experimental results, outlines several theoretical accounts of them, and thenin the best spirit of English compromisecomes to no very definite conclusion about which explanation is best. After seven such chapters even the most dedicated cognitive psychologist is likely to be feeling rather pessimistic. The one certainty is that the discipline will not make progress if it continues to be practised in the same way. Cohen turns to computers, but here she adopts a different expository strategy. She discusses their use only in simulating human behaviour; she ignores the rising discipline of Artificial Intelligence; and she overlooks the role of programs in developing general psychological theories, a very different matter from simulation in that the program is not even supposed to exhibit all the properties of the process that is modelled. Cohen accordingly ends her book with what might reasonably have been its starting point, the current ills of cognitive psychology. She offers no quick or quack remedies, but just a familiar plea that psychologists should aim for a compromise with physiologists. She argues, not for an outright reduction of psychological phenomena to physiological explanations, but for "the cultivation of greater methodological eclecticism". This prescription is presumably fulfilled by the studies of the functional asymmetries between the two cerebral hemispheres, research to which Cohen has contributed, and to which she devotes a chapter of her book. Unfortunately, it has yet to be shown how the localisation of a mental ability to one hemisphere or the other contributes to an understanding of its underlying mechanism.

The Process of Cognition presents a very different diagnosis of cognitive psychology. Blumenthal has stood back from the details of current controversies and written a work that is imbued with an historical perspective and sense of direc- tion. He has eschewed the conventional chapter headings of a text, and based his book on the temporal organisation of experience. He starts with the rapid sensory integrations that yield the perceived flow of events, and works his way through to the mechanisms that give rise to the stability and continuity of mental life. His procedure is essentially inductive. Each chapter begins with a pair of related generalisations, reviews some of their empirical consequences, and closes with their recapitulation. Here, for example, is the generalisation that subsumes the existence of a sensory buffer: "Preattentive buffer delays are delays of inputs to experience at a simple or unstructured level of representation prior to incorporation into central attentional integrations ...". After seven such chapters even the most benighted cognitive psychologist is likely to be feeling mildly optimisticperhaps the discipline is more unified than one had supposed. In the interests of pedagogy, however, Blumenthal has deliberately ignored inconvenient evidence. $\mathrm{He}$ is right to do so: any sort of uniformity is better than being overwhelmed by a chaos of data. Unfortunately, he makes no attempt to move beyond his generalisations to an explanatory theory; and it remains unclear whether he regards such a step as ultimately necessary.

Why is it so difficult to understand the mind? One answer is that psychology is a new science and needs time to develop better methods. The claim is false. Before the Dark Ages of Behaviorism set in, psychologists spent several decades studying mental mechanisms. The two exemplary phenomena described at the outset of this review were, as Blumenthal points out, originally reported in 1879 and 1895 , respectively, though most psychologists probably regard them as recent discoveries. Another view is that psychologists have been too stupid to make progress: any competent physicist could 'get up' the subject in a couple of weeks, and clear up the mess in a couple more. There is no answer to this argument other than to say: come and try; you will be welcome, as any of the physicists, chemists, or engineers, already doing psychology will testify. Perhaps the task is really impossible: the mind can no more elucidate itself than a cabbage can. If so, one can only retort that nature has made the exercise seem damnably and tantalisingly feasible. On the supposition that genuine progress can be made, then perhaps the real problem may be one to which Cohen alludes, the stranglehold of the experimental tradition. One experiment is worth a thousand theories in psychology. Until this imbalance is redressed, students of the mind are unlikely to see very deeply into its workings.

P. N. Johnson-Laird

P. N. Johnson-Laird is Reader in Experimental Psychology at the University of Sussex, $U K$. 